Józef Stala

The Pontifical University of John Paul II in Cracow, Poland

\title{
Rezension \\ Elżbieta Osewska, Edukacja religijna w szkole katolickiej w Anglii i Walii w świetle "Living and Sharing Our Faith. A National Project of Catechesis and Religious Education", Tarnów 2008
}

(Elżbieta Osewska, Der Religionsunterricht an der katholischen Schule in England und Wales im Licht von "Living and Sharing Our Faith. A National Project of Catechesis and Religious Education", Tarnów 2008), Verlag Biblos, 453 Seiten, ISBN 978-83-733267-0-5

„Indem die Katholische Schule ihre eigenständige Sendung erfüllt, nämlich auf systematische und kritische Weise das Kulturgut im Licht des Glaubens zu vermitteln und die Triebkräfte der christlichen Tugenden auszubilden, um so die zweifache Synthese zwischen Kultur und Glauben sowie zwischen Glauben und Leben zu fördern, übersieht sie keineswegs die Wichtigkeit der Unterweisung in der Lehre des Evangeliums, wie sie in der katholischen Kirche überliefert ist. Dieser Unterricht ist tatsächlich ein grundlegender Bestandteil der Erziehungsarbeit, die den Schüler auf die bewusste Wahl eines einsatzbereiten und konsequenten Lebens hin ausrichten will" (Kongegration für das katholische Bildungswesen, Die katholischen Schule, Nr. 49).

Zweifellos stellt der Religionsunterricht ein Grundelement des didaktischen und pädagogischen Prozesses an der katholischen Schule dar. Die katholischen Schulen in Polen sorgen sich auf besondere Weise um den Religionsunterricht und eine katholische Erziehung ihrer Schüler, indem sie beständig nach neuen, modernen und ansprechenden Lösungen suchen. Daher ist dem hier besprochene Buch „Edukacja religijna w szkole katolickiej w Anglii i Walii w świetle Living and Sharing Our Faith. A National Project of Catechesis and Religious Education" mit 
großem Interesse zu begegnen, welches als Habilitationsschrift den Fragenkreis um den Religionsunterricht an den katholischen Schulen in England und Wales aufgreift. Es ist in der Reihe „Rozprawy naukowe” (Wissenschaftliche Arbeiten) im Verlag „Biblos” erschienen.

Zunächst ist zu vermerken, dass dieses Buch die erste derartig umfassende monographische Ausarbeitung in polnischer Sprache ist. Vielmehr gibt es auch in anderen Sprachen keine solche Veröffentlichung, da sich die britischen Experten in ihren Forschungen eher auf die Entstehung und die Entwicklung der katholischen Schulen konzentriert und weniger auf den Religionsunterricht Bezug genommen haben. Darüber hinaus ist der vorliegenden Arbeit auch deshalb großes Interesse entgegen zu bringen, da in polnischer Sprache lediglich Randnotizen oder kurze Artikel über den Religionsunterricht an den staatlichen Schulen in Großbritannien zugänglich sind. Wegen der geringen Zahl polnisch-britischer Kontakte in den Bereichen von Katechese und Religionsunterricht fehlen bisher Arbeiten zu diesem Thema. Folglich ist der immense Kraftaufwand der Autorin umso höher zu schätzen, da sie die Literatur zu ihrem Forschungsgegenstand nicht nur gesammelt und analysiert hat, um sie den polnischen Lesern nahe bringen zu können, sondern auch das Archivmaterial einer tiefgründigen Analyse unterzogen hat, welches im Archiv des Nationalen Projekts zu Katechese und Religionsunterricht „Living and Sharing Our Faith" (London, Eccleston Square 9) lagert.

Die rezensierte Monographie weist eine deutliche und klare Struktur auf. Sie umfasst das Verzeichnis der Abkürzungen, eine Einleitung, vier inhaltlich kohärente Kapitel, die ein umfassendes und ganzheitliches Bild des beleuchteten Fragekreises präsentieren, daneben auch eine Schlussfolgerung, die Bibliographie, eine Liste der Tabellen sowie eine Zusammenfassung in englischer Sprache. Im ersten Kapitel „Kontekst społeczny, polityczny, religijny i edukacyjny w Anglii i Walii” (Der gesellschaftliche, politische, religiöse und erzieherische Kontext in England und Wales) wurde auf den vielschichtigen Kontext in England und Wales eingegangen, da dieser unverzichtbar ist, um die Konzeption des Religionsunterrichts an der katholischen Schule formulieren zu können. Kenntnisreich stellte die Autorin den ethischen, kulturellen und religiösen Pluralismus dar, indem sie auf dessen Ursachen und gesellschaftlichen Auswirkungen verwies. Sie zeigte auch die Situation der katholischen Kirche in England und Wales auf, die trotz Verfolgungen ihre Rolle und Bedeutung in der Gesellschaft allmählich stärken konnte. Darüber hinaus widmete sich die Autorin auch den Veränderungen des englischen und walisischen Erziehungs- und Bildungssystems, insbesondere dem Einfluss einzelner Bildungsreformen auf die Situation des Religionsunterrichts an der staatlichen und der konfessionell geprägten Schule. 
Im zweiten Kapitel „Geneza i rozwój Living and Sharing Our Faith. A National Project of Catechesis and Religious Education" (Genesis und Entwicklung von Living and Sharing Our Faith. A National Project of Catechesis and Religious Education) erläuterte sie die Gründe für die Entstehung und Entwicklung des „Nationalen Projekts”, indem sie dessen Grundsätze in besonderer Weise berücksichtigte, die den Charakter der katholischen Schule, die Erziehung im Sinn einer begleitenden Glaubensentwicklung des Menschen sowie die Vorbereitung von Lehrplan und Schulbüchern für den Religionsunterricht betreffen. Die Autorin unterzog nicht nur die Gründe und die Entwicklung des „Projekts” einer Analyse sondern stellte - bezugnehmend auf die Ergebnisse empirischer Untersuchungen - auch dessen Evaluation vor.

Dagegen erörterte die E. Osewska im dritten Kapitel „Natura, cele i środowiska edukacji religijnej" (Natur, Ziele und Umfelder der Religionserziehung und -bildung) die Dynamik in der Auffassung von der Natur des Religionsunterrichts. Anschließend ging sie auf die Grundsätze des „Projekts” ein und zeigte anhand dessen auf, dass der Religionsunterricht an der katholischen Schule zwar kognitive und erzieherische Ziele erreichen kann, jedoch auch dort nicht imstande ist, die Ziele der Initiation vollständig zu erfüllen. Daraus erwächst der Vorschlag nach einer engen Zusammenarbeit mit den anderen an der Glaubensentwicklung beteiligten Umfeldern, insbesondere mit der Familie und der Pfarrgemeinde. Die Autorin präsentierte nicht nur einzelne Probleme sondern unternahm auch den Versuch, die Grundsätze, die Entwicklung und die Realisierung zu beurteilen.

Im vierten und letzten Kapitel „Kryteria doboru treści i metod w edukacji religijnej" (Kriterien für die Auswahl der Inhalte und der Methoden im Religionsunterricht), in dem die Dokumente zu Katechese und Erziehung der katholischen Kirche in England und Wales sowie die Lehrpläne und die Schulbücher für den Religionsunterricht einer genauen Analyse unterzogen wurden, zeigte die Autorin auf, dass in der ersten Entwicklungsphase des „Projekts” überwiegend theologische Inhalte dominierten. Die Hauptkriterien für die Auswahl bildeten die Heilige Schrift, die katholische Doktrin, die Liturgie sowie existenzielle und religiöse Erfahrung. Später kamen mehr anthropologische und existenzielle Inhalte dazu, obwohl sich das neueste Dokument der katholischen Kirche von England und Wales „Religious Education Curriculum Directory for Catholic Schools" (Richtlinie für den Lehrplan des Religionsunterrichts an katholischen Schulen), das sich mit einem Grundprogramm oder auch mit programmatischen Hinweisen vergleichen lässt, vor allem wieder auf theologische Inhalte beruft, jedoch auf deren Applikation in einem christlichen Leben verweist. 


\section{The Person and the Challenges \\ 244 \\ Volume 1 (2011) Number 2}

Beachtenswert ist die reichhaltige Bibliographie, in der sich sowohl die Dokumente der katholischen Kirche von England und Wales, die im Rahmen des „Projekts” herausgegebenen Programme und Materialien für Religionsunterricht und Katechese, vor allem jedoch Archivmaterial finden lassen, und deren Sammlung die Autorin - aller Vermutung nach - Mut, Selbsthingabe und viel Mühe gekostet hat, damit ihr der Zugang zu dem Archiv gewährt wurde. Darüber hinaus waren eine Vielzahl von Reisen und Aufenthalten in London vonnöten, um eine derartig durchdringende Archivarbeit durchzuführen. Anzuerkennen ist auch die Tatsache, dass das gesamte gesammelte und verwendete Quellenmaterial und die Hilfsliteratur in englischer Sprache steht. Die Benutzung fremdsprachlicher Quellen und Hilfsliteratur führt häufig dazu, dass grammatikalische Strukturen der Fremdsprache einfließen, dagegen gelang es der Autorin in der vorliegenden Arbeit, sich auf schöne, deutliche, klare und gut verständliche wissenschaftliche Art und Weise in der polnischen Sprache auszudrücken. Aus Sicht des polnischen Lesers erscheint es einerseits als wertvoll, in den Fußnoten Fragmente aus den Originalquellen zu präsentieren, und andrerseits den Charakter der Archivdokumente dadurch zugänglich zu machen, dass ihre Bezeichnungen ins Polnische übersetzt wurden. Die Originalbezeichnungen einzelner Archivmaterialien wurden in der Bibliographie aufgelistet. Auch die solide und klar dokumentierten Gedankengänge der Autorin verdienen Beachtung.

Das rezensierte Buch von Dr. habil. Elżbieta Osewska bereichert das polnische Denken im Bereich des Religionsunterrichts um eine neue Perspektive und Herangehensweise. Es schließt eine Lücke in der Literatur Polens zu Katechese, Erziehung und Bildung, wie auch nach der Übersetzung ins Englische in der englischsprachigen Hilfsliteratur. Es scheint angezeigt zu sein, dass die Autorin ihre Forschung weiterführen solle, indem sie diese auf die Konzeption des Religionsunterrichts an nichtkonfessionellen Schulen in England und Wales ausdehnen könnte. Der Religionsunterricht an der katholischen Schule in England und Wales im Licht des „Nationalen Projekts” ist von großem Wert im Hinblick auf die Bildung an der polnischen Schule. Auf diese Weise stellt es eine eigene Aufforderung zur vertieften Analyse und zu weiteren Forschungen dar, und dies nicht nur zum Religionsunterricht an der katholischen Schule sondern ebenso zur Konzeption des Religionsunterrichts an der staatlichen Schule in Polen. Unter anderem aus diesen Gründen verdient es das vorliegende Buch, einen großen Leserkreis zu finden. Vor allem werden all diejenigen davon profitieren, die sich mit Fragen zum Religionsunterricht im Allgemeinen oder in verschiedenen Ländern Europas wie auch zur katholischen Schule befassen. 